\title{
ISOLATED BYPASS GRAFTING OF THE LEFT INTERNAL THORACIC ARTERY TO THE LEFT ANTERIOR DESCENDING CORONARY ARTERY: LATE CONSEQUENCES OF INCOMPLETE REVASCULARIZATION
}

Rosalyn Scott, MD

Eugene H. Blackstone, MD ${ }^{\mathrm{a}, \mathrm{b}}$

Patrick M. McCarthy, MD

Bruce W. Lytle, MD ${ }^{\mathrm{a}}$

Floyd D. Loop, MD ${ }^{\mathrm{a}}$

Jennifer A. White, $M S^{b}$

Delos M. Cosgrove, $\mathrm{MD}^{\mathrm{a}}$
Objective: Multiple strategies to achieve some degree of myocardial revascularization are available. In some, less complete revascularization is accepted to limit invasiveness. To examine the issues of incomplete revascularization, we assessed the long-term impact of additional non-left anterior descending coronary artery stenoses in patients undergoing only grafting of the left internal thoracic artery to the left anterior descending coronary artery.

Methods: A total of 2067 patients underwent primary isolated grafting of the left internal thoracic artery to the left anterior descending coronary artery from 1971 to 1997 . Of these, $26 \%$ and $13 \%$ had 2 - and 3-system disease, respectively. Multivariable analyses of survival and reintervention were performed in the hazard function domain for 27,683 patient-years of follow-up (mean $14 \pm 6.7$ ).

Results: Survival was $99 \%, 88 \%$, and $62 \%$ at 1,10 , and 20 years. Right coronary artery or left circumflex system disease of $50 \%$ or more $(P=.02)$ and particularly high-grade $(\geq 70 \%)$ left circumflex $(P=.01)$ and proximal right coronary artery disease $(P=.01)$, as well as any degree of left main trunk stenosis $(P<.0001)$, were associated with reduced long-term survival. Compared with $75 \%$ 20-year survival in patients with no non-left anterior descending disease, those with either left circumflex or left main trunk disease experienced a $44 \%$ survival, and those with proximal right coronary artery disease, $42 \%$. The most common stated reason for incomplete revascularization was small vessel size. Freedom from reintervention was $89 \%$ and $65 \%$ at 10 and 20 years, respectively. High-grade left main trunk disease, but, in contrast, mid or distal disease of the right coronary artery, and not left circumflex disease, were risk factors for reintervention.

Conclusions: These findings call into question the long-term appropriateness of interventions whose strategy includes leaving unrevascularized segments in territories not in the distribution of the left anterior descending coronary artery. (J Thorac Cardiovasc Surg 2000;120:173-84)
From the Department of Thoracic and Cardiovascular Surgery a and the Department of Biostatistics and Epidemiology, ${ }^{\mathrm{b}}$ The Cleveland Clinic Foundation, Cleveland, Ohio.

Read at the Seventy-ninth Annual Meeting of The American Association for Thoracic Surgery, New Orleans, La, April 18-21, 1999.

Received for publication April 22, 1999; revisions requested Aug 10, 1999; revisions received Feb 22, 2000; accepted for publication March 20, 2000.

Address for reprints: Eugene H. Blackstone, MD, Department of Thoracic and Cardiovascular Surgery, 9500 Euclid Ave, Desk F25, Cleveland, OH 44195 (E-mail: blackse@ccf.org).

Copyright (C) 2000 by The American Association for Thoracic Surgery

0022-5223/2000 $\$ 12.00+0 \quad \mathbf{1 2 / 6 / 1 0 7 2 8 0}$

doi: $10.1067 / \mathrm{mtc} .2000 .107280$ pe common goal of operations for coronary bypass Grafting has been complete revascularization. This goal has been based on logic and on studies from the past that have shown in a general way that complete revascularization was associated with better long-term survival. ${ }^{1-7}$ Realistically, it has been difficult to define complete revascularization and to separate the effect of incomplete revascularization as a surgical strategy from the possibility that incomplete revascularization is a marker for worse coronary artery disease or, perhaps, a more rapid rate of progression of coronary artery disease.

Currently, multiple avenues to achieve some degree of myocardial revascularization are available. In some of 
Table I. Coronary lesions, cardiac function, symptoms, and comorbidity of patients undergoing LITA-LAD grafting

\begin{tabular}{|c|c|c|}
\hline Variables & No. & $\%$ of 2067 \\
\hline \multicolumn{3}{|l|}{ Coronary anatomy } \\
\hline \multicolumn{3}{|l|}{ Extent of disease (50\% criterion) } \\
\hline Single-system & 1274 & 62 \\
\hline Two-system & 533 & 26 \\
\hline Three-system & 260 & 13 \\
\hline \multicolumn{3}{|l|}{ Left main disease } \\
\hline None & 1902 & 92 \\
\hline$>0$ & 165 & 8 \\
\hline$\geq 50 \%$ & 29 & 2 \\
\hline \multicolumn{3}{|l|}{ Coronary dominance } \\
\hline Right & 1469 & 71 \\
\hline Left & 311 & 15 \\
\hline Codominant & 242 & 12 \\
\hline Unknown & 45 & 2 \\
\hline \multicolumn{3}{|l|}{ Left ventricular dysfunction } \\
\hline None & 1352 & 65 \\
\hline Mild & 520 & 25 \\
\hline Moderate & 154 & 8 \\
\hline Severe & 41 & 2 \\
\hline \multicolumn{3}{|l|}{ Angina limitation } \\
\hline None & 302 & 15 \\
\hline Mild & 647 & 31 \\
\hline Moderate & 216 & 10 \\
\hline Severe & 902 & 44 \\
\hline \multicolumn{3}{|l|}{ Comorbidity } \\
\hline $\begin{array}{l}\text { Pharmacologically treated } \\
\text { diabetes (missing data in 214) }\end{array}$ & 145 & 8 \\
\hline Smoking history (missing data in 257) & 942 & 52 \\
\hline Previous MI (missing data in 2) & 847 & 41 \\
\hline PVD (missing data in 2) & 120 & 6 \\
\hline Renal failure (missing data in 2) & 6 & 0.3 \\
\hline
\end{tabular}

LITA-LAD, Left internal thoracic artery-left anterior descending coronary artery; $M I$, myocardial infarction; $P V D$, peripheral vascular disease.

the strategies, percutaneous and operative, less complete revascularization is accepted to limit the invasiveness of the procedure. Part of the logic behind these strategies is the thought that the left internal thoracic artery to left anterior descending coronary artery (LITA-LAD) graft is so important that revascularization of other areas is relatively unimportant. Our previous studies of patients receiving LITA-LAD grafts have shown that nonsignificant disease in the territories of the right coronary artery (RCA) and left circumflex coronary artery (LCx) system is a predictor of late events. ${ }^{8}$ However, to examine with a larger patient subset the prognostic issues of incomplete revascularization in patients who already have significant stenoses, we studied 2067 patients undergoing operation with an isolated LITA graft solely to the LAD during the years 1971 through 1996, with follow-up extending to 25 years.

\section{Patients and methods}

Study group. A total of 2067 patients undergoing isolated grafting of the LITA to the LAD as their sole coronary intervention, for the first time, without concomitant procedures, using a conventional median sternotomy and cardiopulmonary bypass, during the years 1971 through 1996, were identified by means of the Cardiovascular Information Registry (CVIR) at The Cleveland Clinic Foundation. The only patients excluded were those undergoing less invasive surgery and "off-pump" surgery. Demographic, clinical, coronary angiography, surgical, and complication variables were abstracted essentially concurrently with clinical events into the prospective CVIR database. Of the 2067 patients, $1674(81 \%)$ were men and $393(19 \%)$ women. The mean age at operation was $54 \pm 9.0$ years, ranging from 26 to 83 years. Table I summarizes other characteristics of these patients.

Follow-up. CVIR personnel follow up the first 1000 patients per year undergoing primary elective isolated coronary bypass grafting at 5 -year intervals. Those patients in the present study group not part of this routine follow-up were contacted by telephone in the summer of 1998. Twenty-seven $(1.3 \%)$ were lost to follow-up, most of whom were foreign patients. Total follow-up was 27,683 patient-years, mean 14 \pm 6.7 years. The longest follow-up was 25.8 years. Among survivors, $89 \%$ have been followed up for 5 years or more, $71 \%$ for 10 years or more, $54 \%$ for 15 years or more, $32 \%$ for 20 years or more, and $2 \%$ for 25 years or more.

Angiographic data. Stenoses were recorded by CVIR abstractors from the catheterization report for each coronary system as follows. For the LAD system, the maximal stenosis was recorded in the proximal, mid, and distal portions of the LAD, the diagonal branches, a major septal artery, and the ramus intermedius coronary artery if it originated from the LAD. For the LCx system, the maximal stenosis was recorded in the proximal LCx, the lateral branches, posterolateral segments, in the ramus intermedius if it came off the circumflex, and in the posterior descending coronary artery if it originated from the LCx in a left dominant pattern. For the RCA system, the maximal stenosis was recorded in the proximal, mid, and distal RCA, right marginals, and posterior descending coronary artery and posterolateral segments in right dominant patterns.

Incomplete revascularization. We defined incomplete revascularization as the presence of stenosis in the $\mathrm{LCx}$ or RCA systems of $50 \%$ or greater. This definition assumes that (1) the LITA-LAD graft allows complete perfusion of the LAD system and (2) stenosis of the left main trunk is managed separately in the analyses. In addition to this arbitrary, global dichotomous variable, we investigated the overall maximal LCx and RCA system stenoses, as well as stenosis in each of the segments cited above. For this we used both the "continuous" percent stenosis and variables representing three discrete criteria: (1) stenosis greater than 0 (any stenosis), (2) stenosis of $50 \%$ or greater diameter reduction, and (3) stenosis of $70 \%$ or greater diameter reduction. 
To verify the quality of this information, and to ascertain the recorded reasons non-LAD lesions were not bypassed, we selected a $10 \%$ random sample of cases with lesions in the RCA or LCx system greater than or equal to $50 \%$ for detailed study. For this, the uniform pseudorandom number generator in the SAS system software (SAS Institute, Inc, Cary, NC) was used. Because of systematic discard of angiograms by the institution and missing records, a total of 268 random records were randomized to obtain the requisite 206 complete records. All coronary angiography reports were reviewed, which in most cases included prints of representative angiographic frames rather than original angiographic films that had been destroyed or returned to the referring institution. For patients catheterized elsewhere, both the outside catheterization report and the report of its review by Cleveland Clinic Foundation cardiologists were examined. Recommendations made by cardiologists preoperatively were recorded. Each operative report was reviewed, along with any other records, such as letters to referring physicians, to record reasons for incomplete revascularization.

Data analysis. The end points for this study were two: (1) all-cause mortality from the time of LITA-LAD grafting and (2) reintervention, either by percutaneous revascularization of any kind (generically designated percutaneous transluminal coronary angioplasty [PTCA]) or reoperation. The primary objective of the data analysis was to determine the association, if any, between unbypassed lesions in the non-LAD coronary systems (left main, LCx, RCA) and these timerelated events. Secondary objectives included investigating the pattern of incomplete revascularization across time and identifying the reasons for incomplete revascularization.

Nonparametric estimates of survival and freedom from reintervention were obtained by the method of Kaplan and Meier. ${ }^{9}$ A parametric method* was used to resolve the number of phases of instantaneous risk of death (hazard function) and to estimate their shaping parameters. ${ }^{10}$

The potential risk factors (variables) obtained from the CVIR database were organized for analysis as in Appendix Table I. Exploratory analyses of these variables included correlation analysis, stratified life table analyses, and decile risk analysis of ordinal and continuous variables to determine possible transformations of scale needed to properly calibrate the variables to outcome.

Multivariable analyses were performed with particular attention to the details of the unbypassed coronary stenoses. Specific so-called interaction analyses were conducted of the coronary lesions identified as risk factors with the pattern of coronary artery dominance, left ventricular function, age, and diabetes. Interaction analysis was also performed of incomplete revascularization (see below). The analyses used a directed technique of entry of variables into the multivariable models. ${ }^{11}$ The $P$ value criterion for retention of variables in the final models was .05 .

*Available by anonymous ftp from ftp://uabcvsr.cvsr.uab.edu
Multivariable logistic regression analysis was used to identify the characteristics of patients with incomplete revascularization. For this, all patient variables were examined, but the only coronary artery variables incorporated into the analysis were those related to the pattern of coronary dominance.

Presentation. Because few patients were followed up longer than 25 years, graphical presentations were truncated at 25 years. Nonparametric Kaplan-Meier time-related estimates are presented as discrete symbols accompanied by asymmetric confidence limits (CL) equivalent to $1 \mathrm{SE} .{ }^{12}$ Smooth, solid curves, which are superimposed on the symbols, are completely independent parametric estimates of the distribution of intervals to death or reintervention. These are accompanied by confidence limits equivalent to $1 \mathrm{SE} .{ }^{10}$

For informal survival comparison and reference, a predicted US population life table was generated for each patient, specific to his or her sex and age at the time of the operation. These tables were averaged to portray an age-sex-matched population life table. For some comparisons, individual curves were generated for each patient from the multivariable equations and averaged within strata. ${ }^{13}$ These were compared with stratified Kaplan-Meier estimates.

For comparisons of survival in patients with disease other than in the LAD system, a cohort of 682 patients was identified with no recognized obstruction of any degree (not just nonsignificant obstruction) in the left main trunk, LCx system, or RCA system. For clarity, only parametric estimates of this cohort are portrayed.

\section{Results}

Incomplete revascularization. The prevalence of incomplete revascularization $(50 \%$ or greater lesions in either the RCA or LCx systems) fell from about $60 \%$ to $20 \%-25 \%$ by the early 1980 s and remained at those levels (Fig 1). The most common reason recorded for not grafting non-LAD vessels was that the arteries were too small (Table II). In a few cases, specific problems with conduit availability or unavailability of a site for aortic graft attachment were recorded. In a few cases, available records did not indicate the presence of nonLAD lesions of $50 \%$ or more, and in 3 cases $(1.5 \%)$, data entry was erroneous.

Correlates of incomplete revascularization included men, old age, greater left ventricular dysfunction, previous myocardial infarction, a left dominant coronary circulation, diabetes, higher cholesterol level, peripheral vascular disease, and earlier date of operation (Table III).

Survival. Risk-unadjusted survival was $99.1 \%, 96 \%$, $88 \%, 76 \%, 62 \%$, and $48 \%$ at $1,5,10,15,20$, and 25 years after LITA-LAD grafting, respectively (Fig 2). The instantaneous risk of death was highest immediately after operation, fell to a low level, and then began to rise steadily about 6 months after the operation (Fig 


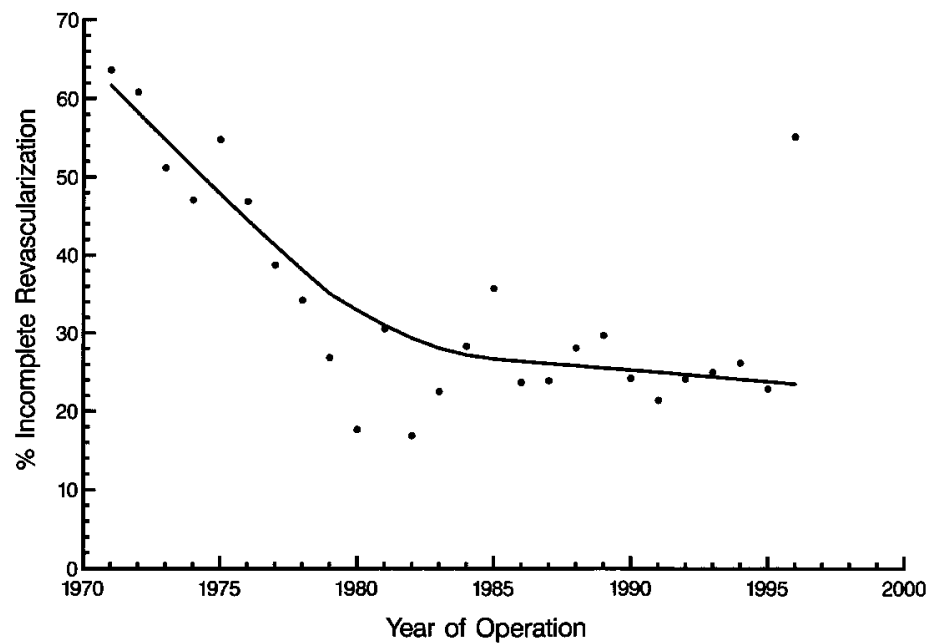

Fig 1. Prevalence of incomplete revascularization across calendar date. The filled circles represent the proportion of each calendar year's LITA-LAD grafting cases with incomplete revascularization, defined as $50 \%$ or greater obstructions in the RCA or LCx coronary systems. The solid line is a Lowes approximation to the distribution of this prevalence, performed in S-Plus with the use of default options. ${ }^{28}$

Table II. Recorded reasons for incomplete revascularization

\begin{tabular}{lrc}
\hline \multicolumn{1}{c}{ Reason } & $n$ & \% of 206 \\
\hline Small and/or severely diseased artery & 92 & 45 \\
No reason recorded & 67 & 33 \\
CABG not justified (operative note) & 10 & 4.9 \\
Nondominant diseased RCA & 5 & 2.4 \\
No suitable conduit (eg, vein graft) available & 4 & 1.9 \\
Intramyocardial vessel could not be found & 2 & 1.0 \\
Posterior coronary artery inaccessible & 2 & 1.0 \\
Infarcted area & 1 & 0.5 \\
Not a vessel normally bypassed & 1 & 0.5 \\
Inadequate data & 3 & 1.5 \\
LITA-LAD grafting incorrectly coded & & \\
$\quad$ and subsequently removed) & 3 & 1.5 \\
No non-LAD disease $\geq 50 \%$ on review & 13 & 6.3 \\
$\quad$ of available records & & \\
Total & 206 & 100 \\
\hline
\end{tabular}

$C A B G$, Coronary artery bypass grafting; $L A D$, left anterior descending coronary artery; LITA, left internal thoracic artery; $R C A$, right coronary artery.

$2, B)$. By way of orientation, this hazard function was similar to that predicted for the age-sex-matched US population after about 8 years. The hazard function consisted of a brief early phase, a small constant hazard phase, and a late rising hazard phase. The early hazard phase accounted for only 9 deaths, the constant hazard phase for 111, and the late hazard phase for 453 . Thus, in the nonproportional hazards multivariable models, a risk factor in the late hazard phase of similar magnitude to one in the constant hazard phase will have many times larger impact on survival.
Table III. Correlates of incomplete revascularization (unbypassed stenoses $\geq 50 \%$ in LCx or RCA systems)

\begin{tabular}{|c|c|c|c|}
\hline Correlate & $\begin{array}{c}\text { Logistic } \\
\text { coefficient } \pm S D\end{array}$ & $\begin{array}{l}\text { Direction of } \\
\text { influence }\end{array}$ & $\mathrm{P}$ value \\
\hline \multicolumn{4}{|l|}{ Demography } \\
\hline Men & $0.56 \pm 0.138$ & $\uparrow$ & $<.0001$ \\
\hline Age $^{*}$ & $0.96 \pm 0.140$ & $\uparrow$ & $<.0001$ \\
\hline \multicolumn{4}{|l|}{$\mathrm{LV}$ function } \\
\hline $\mathrm{LV}_{\text {dysfunction }}^{\dagger}$ & $1.27 \pm 0.133$ & $\uparrow$ & $<.0001$ \\
\hline Previous MI & $0.78 \pm 0.137$ & $\uparrow$ & $<.0001$ \\
\hline $\begin{array}{l}\text { Left dominant coronar } \\
\text { circulation }\end{array}$ & $0.62 \pm 0.138$ & $\uparrow$ & $<.0001$ \\
\hline \multicolumn{4}{|l|}{ Noncardiac comorbidity } \\
\hline Diabetes & $0.54 \pm 0.20$ & $\uparrow$ & .007 \\
\hline Cholesterol level ${ }^{\ddagger}$ & $1.49 \pm 0.27$ & $\uparrow$ & $<.0001$ \\
\hline PVD & $0.81 \pm 0.22$ & $\uparrow$ & .0002 \\
\hline Date of operation ${ }^{\S}$ & $-0.87 \pm 0.075$ & $\downarrow$ & $<.0001$ \\
\hline Intercept & -9.3 & & \\
\hline
\end{tabular}

$L V$, Left ventricular; $M I$, myocardial infarction; $P V D$, peripheral vascular disease; $S D$, standard deviation.

"[age $/ 50]^{2}$ squared transformation.

${ }^{\dagger} \ln [L V$ dysfunction grade] logarithmic transformation.

${ }^{\ddagger} \ln [$ cholesterol level, $\mathrm{mg} / \mathrm{dL}$ ] logarithmic transformation.

$\$$ In[years since 1/1/1971] logarithmic transformation.

Incremental risk factors for death included older age, left ventricular dysfunction, and a history of previous myocardial infarction, peripheral vascular disease, and diabetes (Table IV). In addition, survival was less in patients with left main trunk stenosis of any degree, with incomplete revascularization ( $\geq 50 \%)$ of the $\mathrm{LCx}$ and RCA, with high-grade $(\geq 70 \%)$ stenosis in the LCx system, and with high-grade proximal RCA stenosis. 

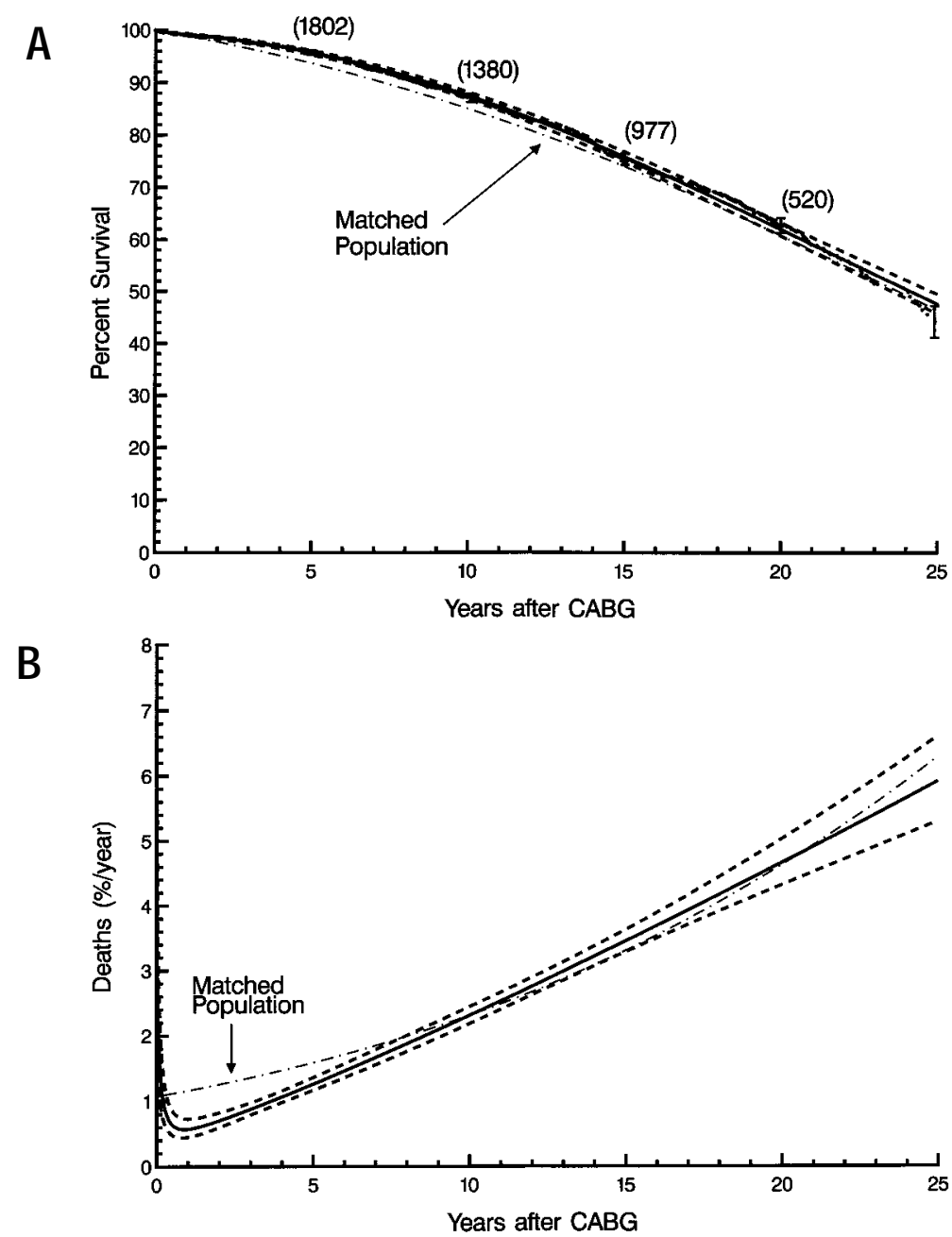

Fig 2. Survival after LITA-LAD conventional coronary artery bypass grafting $(C A B G)$. A, Survival. The nonparametric (small dots) and parametric (smooth curves) estimates are presented as described in the "Methods" section. The dash-dot-dash line is an age-sex-matched US population life table estimate for these same patients. B, Hazard function.

Left main trunk disease. Lesions in the left main trunk at the time of LITA-LAD grafting were recognized in 165 patients. Stenosis of any degree in the left main trunk was a risk factor for late death (Table IV). To illustrate the impact of left main trunk disease on survival using raw data, Fig 3 compares patients with left main lesions of any degree (unadjusted for other lesions and patient characteristics) with the subgroup patients having no recognized obstructions other than that in the LAD system. At 20 years, survival was $44 \%$ (CL 39\%$49 \%$ ) for patients with any degree of left main disease (Table V) compared with 75\% (CL 72\%-77\%).

Correlates of unbypassed left main trunk disease of any degree included men, older age, greater left ventricular dysfunction, peripheral vascular disease, and earlier date of operation (Table VI).
LCX coronary system disease. High-grade $(\geq 70 \%)$ LCx system disease was present preoperatively in 301 patients (Table V). At 20 years, survival among these patients was 44\% (CL 41\%-47\%) (Fig 5). Those with disease in the lateral LCx branches fared somewhat worse (Fig 5, Table V); their increased risk occurred somewhat earlier than it did with other LCx system lesions (constant hazard phase, Table IV).

$R C A$ system disease. Patients with high-grade proximal RCA lesions, present in 228, had a 42\% (CL 38\%46\%) 20-year survival (Table V). Their survival was worse compared with a group of patients with RCA system disease ( $\geq 50 \%)$, including those with proximal RCA disease between $50 \%$ and $70 \%$, but without left main or LCx disease of any degree (Fig 6). Survival of both these groups, however, was worse than that for the 
Table IV. Incremental risk factors for death after LITA-LAD grafting

\begin{tabular}{|c|c|c|c|}
\hline Incremental risk factor & Coefficient $\pm S D$ & Direction of influence & $\mathrm{P}$ value \\
\hline \multicolumn{4}{|l|}{ Early hazard phase } \\
\hline None & - & & - \\
\hline \multicolumn{4}{|l|}{ Constant hazard phase } \\
\hline Left main trunk stenosis of any degree & $1.04 \pm 0.24$ & $\uparrow$ & $<.0001$ \\
\hline Incomplete revascularization of $\mathrm{LCx}$ or $\mathrm{RCA}^{*}$ & $0.59 \pm 0.25$ & $\uparrow$ & .02 \\
\hline LCx lateral branch disease $\geq 70 \%$ & $0.73 \pm 0.30$ & $\uparrow$ & .01 \\
\hline Increasing grade of LV dysfunction & $0.50 \pm 0.122$ & $\uparrow$ & $<.0001$ \\
\hline History of previous MI & $0.65 \pm 0.28$ & $\uparrow$ & .02 \\
\hline \multicolumn{4}{|l|}{ Late hazard phase } \\
\hline LCx system disease (any location) $\geq 70 \%$ & $0.36 \pm 0.149$ & $\uparrow$ & .02 \\
\hline RCA proximal disease $\geq 70 \%$ & $0.42 \pm 0.165$ & $\uparrow$ & .01 \\
\hline Older age & $0.092 \pm 0.0100$ & $\uparrow$ & $<.0001$ \\
\hline PVD & $0.69 \pm 0.20$ & $\uparrow$ & .0004 \\
\hline Diabetes, pharmacologically treated & $0.75 \pm 0.184$ & $\uparrow$ & $<.0001$ \\
\hline
\end{tabular}

$L C x$, Left circumflex; LITA-LAD, left internal thoracic artery-left anterior descending coronary artery; $L V$, left ventricular; $M I$, myocardial infarction; $P V D$, peripheral vascular disease; $R C A$, right coronary artery; $S D$, standard deviation.

"Unbypassed stenoses $>50 \%$.

Table V. Survival after LITA-LAD grafting, overall and in subgroups

\begin{tabular}{|c|c|c|c|c|c|c|c|c|c|c|c|c|c|}
\hline \multirow[b]{2}{*}{ Group } & \multicolumn{3}{|c|}{ One year } & \multicolumn{3}{|c|}{ Five years } & \multicolumn{3}{|c|}{ Ten years } & \multicolumn{4}{|c|}{ Twenty years } \\
\hline & $n$ & $\%$ & $C L(\%)$ & $n^{*}$ & $\%$ & $C L(\%)$ & $n^{*}$ & $\%$ & $C L(\%)$ & $n^{*}$ & $\%$ & $C L(\%)$ & $n^{*}$ \\
\hline Overall & 2067 & 99.1 & 98.9-99.3 & 2003 & 95.7 & $95.2-96.1$ & 1802 & 88 & $87-88$ & 1380 & 62 & $61-63$ & 520 \\
\hline Complete revascularization ${ }^{\dagger}$ & 1276 & 99.4 & $99.2-99.6$ & 1244 & 97.3 & $96.7-97.7$ & 1127 & 91.1 & $90.1-91.9$ & 893 & 70 & $68-71$ & 286 \\
\hline Incomplete revascularization & 791 & 98.3 & 97.8-98.7 & 758 & 93.1 & $92.1-93.9$ & 665 & 81 & $80-83$ & 502 & 53 & $51-55$ & 218 \\
\hline No non-LAD disease ${ }^{\S}$ & 682 & 99.6 & 99.4-99.8 & 664 & 97.8 & $97.1-98.3$ & 600 & 93.6 & $92.6-94.5$ & 455 & 75 & $72-77$ & 150 \\
\hline Any left main trunk disease & 165 & 97.0 & $95.3-98.0$ & 159 & 90 & $87-92$ & 136 & 71 & $67-75$ & 86 & 44 & $39-49$ & 32 \\
\hline$>70 \%$ LCx system disease & 301 & 98.6 & $97.8-99.2$ & 291 & 90 & $89-92$ & 247 & 73 & $70-76$ & 173 & 44 & $41-47$ & 74 \\
\hline$>70 \%$ LCx-lateral disease & 89 & 98.9 & $97.0-99.6$ & 87 & 84 & $80-88$ & 67 & 67 & $61-72$ & 46 & 41 & $35-48$ & 13 \\
\hline$>70 \%$ proximal RCA disease & 228 & 98.2 & 97.1-98.9 & 220 & 91 & $89-93$ & 188 & 76 & 73-79 & 133 & 42 & $38-46$ & 34 \\
\hline
\end{tabular}

$C L, 70 \%$ confidence limits; $L A D$, left anterior descending; $L C x$, left circumflex; $L I T A-L A D$, left internal thoracic artery-left anterior descending coronary artery; $R C A$, right coronary artery.

*Number of patients alive and traced after this time interval.

$\uparrow<50 \%$ stenosis in RCA or LCx systems.

$\$ \geq 50 \%$ stenosis in RCA or LCx systems.

$\S$ No disease of any degree recorded in left main, LCx, or RCA systems.

cohort of patients with no disease appreciated outside the LAD.

Reintervention. Freedom from reintervention by PTCA or reoperation was $89 \%$ and $65 \%$ at 10 and 20 years postoperatively (Fig 7). Risk factors for reintervention included earlier date of operation, paralleling the higher prevalence of incomplete revascularization in the early time period (see Fig 1), but were further complicated by the introduction of percutaneous methods in the 1980s (Table VII). Importantly, disease in the mid and distal RCA were risk factors for reintervention, in contrast to the association of proximal RCA disease and death in the dominating late phase of hazard. LCx disease was associated with a reduced rate of reintervention, even though it increased the risk of death. The small number of patients with high-grade $(\geq 70 \%)$ left main trunk disease came rapidly to reintervention, but not those with less severe grades of stenosis.

\section{Discussion}

Principal findings. The clearest lesson from this study is that, by itself, the LITA-LAD graft does not fully compensate for the presence of disease in other coronary systems. Certainly, the LITA-LAD graft is the most important part of the bypass operation for most patients. The long-term patency of LITA-LAD grafts is the best of any grafting strategy, and clinical studies have shown that the LITA-LAD graft leads to improved late survival and decreased late cardiac events after operations for either single or multivessel disease.$^{8,14-19}$ However, in this study the patients with unbypassed lesions in the proximal RCA or in the 


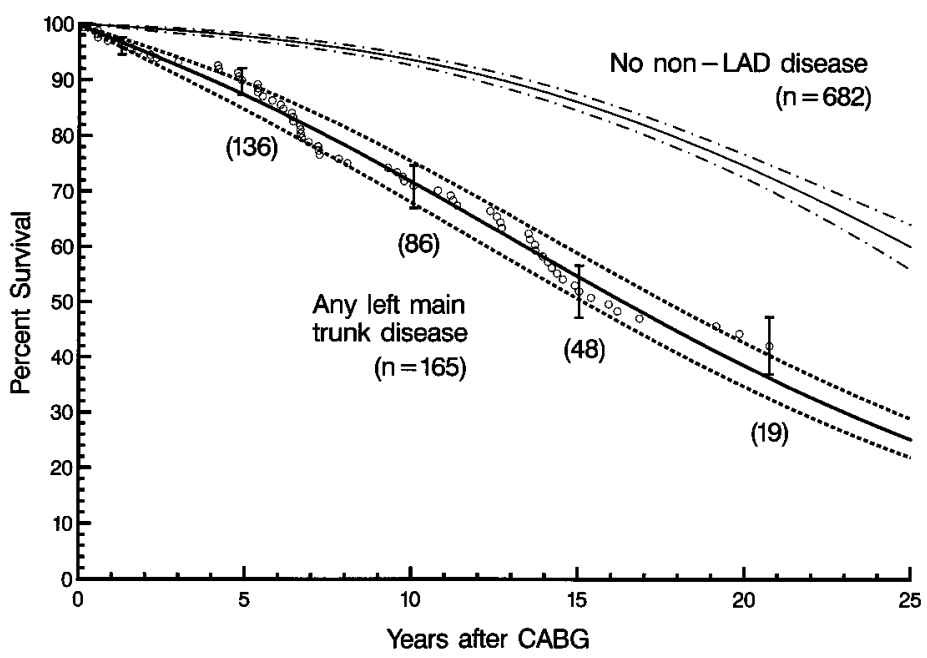

Fig 3. Survival impact of incomplete revascularization. Survival, depicted as in Fig 1, is shown for LITA-LAD grafting patients stratified according to the presence (incomplete revascularization, open circles) or absence (complete revascularization, filled circles) of important (50\% or more diameter obstruction) lesions in non-LAD systems.

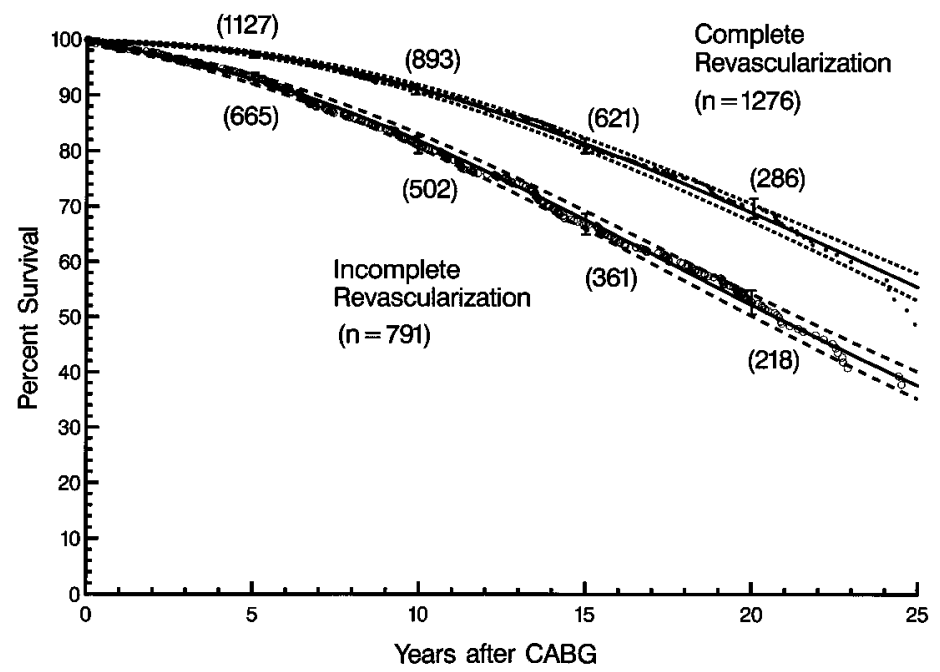

Fig 4. Effect of left main disease on survival. Patients with any left main disease at the time of isolated LITA-LAD grafting are shown by the open circles and parametric curves. The upper parametric curves represent a risk-unadjusted depiction of all patients with absence of lesions in the left main trunk or RCA or LCx systems (no non-LAD disease).

LCx coronary artery, or any lesion (regardless of severity) in the left main coronary artery, had importantly worse survival than patients without those lesions. The magnitude of the difference between completely and incompletely revascularized patients was substantial and became particularly striking in the second decade after operation.

The mechanism for these findings is not clear. Was the increased rate of late death related to the ischemic burden existing at the time of operation, or were these unbypassed lesions markers of a more severe atherogenic diathesis that produced more aggressive progression of native vessel disease during the follow-up period? Our data do not allow us to say. We sought to gain some insight by examining the reasons for incomplete revascularization. Incomplete revascularization was more common in the early years of the coronary bypass era and was usually based on the thought that the unbypassed arteries were not important because of small size or infarction in their distribution. However, 


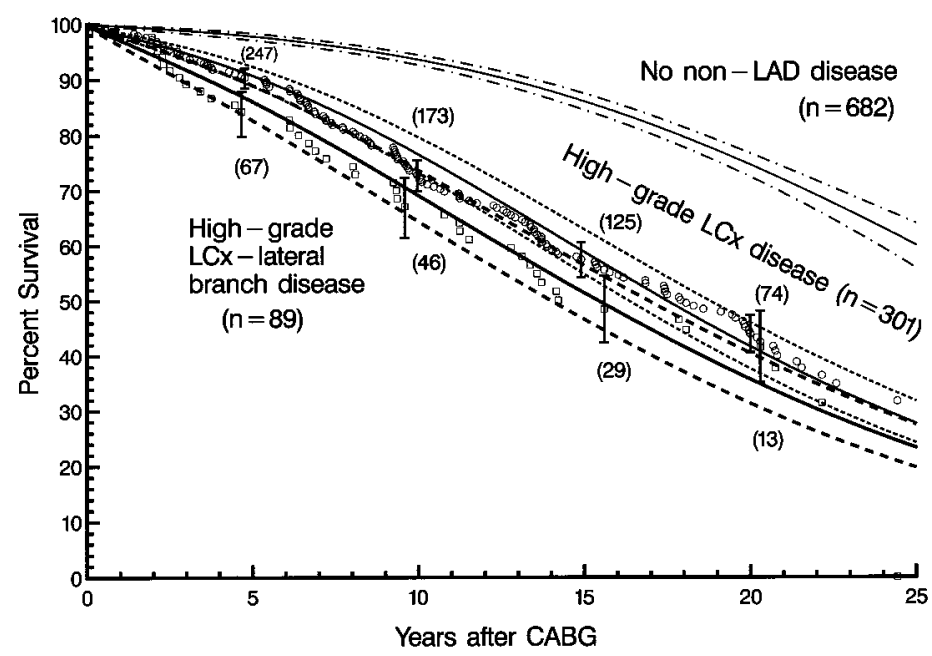

Fig 5. Impact of LCx system disease on survival. Survival is depicted as in Fig 4, where the circles and lighter parametric curves represent patients with high-grade (70\% or more) lesions in any portion of the LCx system and the squares and heavy parametric curves represent a subset of these patients with high-grade lesions in the lateral branches of the LCx system.

Table VI. Correlates of left main trunk disease of any degree

\begin{tabular}{lccc}
\hline Correlate & $\begin{array}{c}\text { Logistic coefficient } \\
\pm S D\end{array}$ & $\begin{array}{c}\text { Direction of } \\
\text { influence }\end{array}$ & P value \\
\hline Demography & & & \\
$\quad$ Men & $0.48 \pm 0.23$ & $\uparrow$ & .04 \\
$\quad$ Age & $0.049 \pm 0.0097$ & $\uparrow$ & $<.0001$ \\
LV dysfunction & $0.35 \pm 0.099$ & $\uparrow$ & .0004 \\
PVD & $1.16 \pm 0.25$ & $\uparrow$ & $<.0001$ \\
Date of operation & $0.70 \pm 0.31$ & $\downarrow$ & .02 \\
Intercept & -6.3 & &
\end{tabular}

$L V$, Left ventricular; $P V D$, peripheral vascular disease; $S D$, standard deviation. *1/[years since 1/1/1971] inverse transformation.

they may have been more important than originally recognized.

A second important observation is that left main stenosis of any degree predicted decreased late survival. Again, the question arises whether the negative impact of seemingly "nonsignificant" left main stenoses was related to an underestimation of those stenoses at the time of operation or the rate of subsequent disease progression. Angiographic evaluation of left main coronary lesions can be difficult, and considerable interobserver and intraobserver variability has been noted. ${ }^{20,21}$ Intravascular ultrasound has documented the presence of important disease in patients for whom angiograms did not clearly document left main stenosis and may provide a more accu- rate means for assessing the left main coronary artery in the future. ${ }^{22}$

A third lesson from the study is that the likelihood of reintervention may be associated with variables that are not associated with the risk of death, for example, ungrafted distal RCA stenoses. Sergeant, Blackstone, and Meyns ${ }^{23}$ have made that observation in the assessment of large numbers of patients with multivessel disease as well.

Importance of incomplete revascularization. The advent of percutaneous and less invasive surgical approaches to myocardial revascularization has raised the issue of the importance of complete revascularization, because those strategies are less consistently able to achieve complete revascularization than standard surgical methods. ${ }^{24,25}$ The concept of "functionally adequate revascularization"-restoration of perfusion to vessels judged bypassable that supply normal myocardium-has arisen from the interventional cardiology literature. ${ }^{26}$ Some studies of small numbers of patients with multivessel disease undergoing PTCA have not demonstrated a significant difference in 1-year survival when comparing patients receiving "functionally adequate" versus "complete" revascularization. ${ }^{26}$ However, those observations are not clearly applicable to the surgical situation. First, patients undergoing multiple PTCAs during the time period when these studies were conducted tended to be patients who were not at a high risk of short-term death regardless of treatment success. ${ }^{24-26}$ Second, the follow-up interval of 1 year has little relationship to long- 


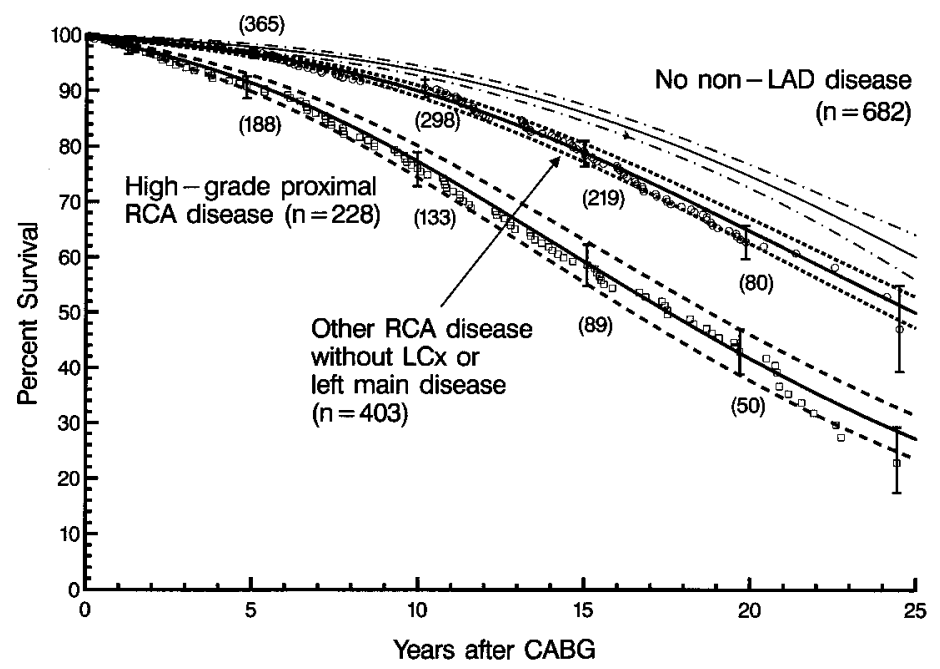

Fig 6. Impact of RCA system disease on survival. The depiction is as in Fig 4. The circles represent patients with high-grade (70\% or more) lesions in the proximal RCA. In contrast, patients with RCA system disease of $50 \%$ or more and without left main or LCx disease (with or without other disease in the LCx system) are shown by the squares. These latter patients were not shown by multivariable analysis to be at increased risk of late mortality (Table IV).

Table VII. Incremental risk factors for reintervention after LITA-LAD grafting

\begin{tabular}{|c|c|c|c|}
\hline Incremental risk factor & Coefficient $\pm S D$ & Direction of influence & $\mathrm{P}$ value \\
\hline \multicolumn{4}{|l|}{ Early hazard phase } \\
\hline Date of operation & $0.152 \pm 0.044$ & $\uparrow$ & .0006 \\
\hline \multicolumn{4}{|l|}{ Late hazard phase } \\
\hline Left main trunk disease $\geq 70 \%$ & $2.2 \pm 0.49$ & $\uparrow$ & $<.0001$ \\
\hline LCx proximal disease $\geq 50 \%$ & $-1.08 \pm 0.43$ & $\downarrow$ & .01 \\
\hline LCx lateral disease $\geq 70 \%$ & $-1.30 \pm 0.50$ & $\downarrow$ & .01 \\
\hline RCA mid disease of any degree & $0.37 \pm 0.116$ & $\uparrow$ & .001 \\
\hline RCA distal disease of any degree & $0.40 \pm 0.155$ & $\uparrow$ & .01 \\
\hline Age $^{*}$ & $-4.2 \pm 1.60$ & $\downarrow$ & .009 \\
\hline Date of operation ${ }^{\dagger}$ & $0.104 \pm 0.043$ & $\downarrow$ & .02 \\
\hline
\end{tabular}

$L C x$, Left circumflex; LITA-LAD, left internal thoracic artery-left anterior descending coronary artery; $R C A$, right coronary artery; $S D$, standard deviation. ${ }^{*}$ age $\left./ 50\right]^{2}$ squared transformation, supplemented by a slight shaping of untransformed age (coefficient $0.146 \pm 0.066, P=.03$ ).

${ }^{\dagger}[1 / \text { number of years since } 1 / 1 / 1971]^{2}$ squared inverse transformed shape prolonged by untransformed date of operation (coefficient $0.066 \pm 0.0130, P<.0001$ )

term survival considerations. Third, patients undergoing PTCA are at a relatively high risk of failure of treatment (restenosis) even in those vessels that are treated, making differences between complete and incomplete treatment relatively smaller. Fourth, patients with incomplete revascularization after PTCA are more apt to come to surgical revascularization that may improve their survival. It is of interest that the characteristics of PTCA patients receiving "functionally adequate revascularization" appear to be similar to our patients who received "incomplete revascularization," a group who had inferior long-term outcomes despite LITA-LAD grafting.
Limitations. This study has obvious limitations. It is an observational clinical study. We did not have data regarding myocardial viability or serial angiographic data related to disease progression. The ideal control group, patients with similar multivessel lesions who did not receive bypass grafts, does not exist. Although we infer that complete revascularization might improve outcomes, the evidence for that is indirect and untested.

However, these data do provide some insight into complete revascularization and late outcome. Previous studies of complete versus incomplete revascularization have involved groups of patients with multivessel 


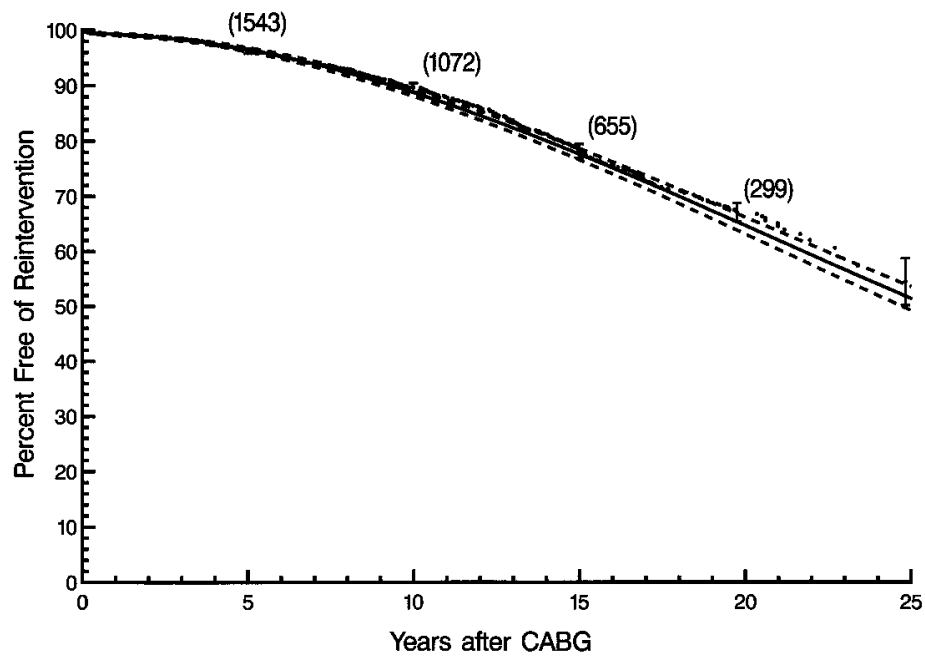

Fig 7. Freedom from reintervention (either PTCA or reoperation). The depiction is as in Fig 2.

disease, few of whom received internal thoracic artery grafts. Today, it might be argued that, so long as LAD revascularization is secure with a LITA-LAD graft, revascularization of the other coronary systems does not influence survival and can be either ignored or approached with techniques less likely to lead to longterm patency. The data in this study argue against that concept. Over a 20-year follow-up, the LAD revascularization, while important, is not all-important.

Clinical inferences. As we move into a differently invasive era, techniques of revascularization and combinations of techniques of revascularization will be developed that are appropriate for different situations. Complete revascularization is not the only thing that is important about revascularization strategies, and considerations of periprocedure morbidity always must be strongly considered. However, over the long term, the status of the LAD coronary artery is not the only thing that influences survival.

We thank Penny Houghtaling, MS, for her biostatistical expertise; Colleen Vahcic, Karen Mrazeck, William Blackstone, and DeDe Orraca-Tetteh for data collection and patient follow-up; and Lucinda Mitchin for manuscript preparation.

\section{REFERENCES}

1. Bell MR, Gersh BJ, Schaff HV, Holmes DR Jr, Fisher LD, Alderman EL, et al. Effect of completeness of revascularization on long-term outcome of patients with three-vessel disease undergoing coronary artery bypass surgery: a report from the
Coronary Artery Surgery Study (CASS) registry. Circulation 1992;86:446-457.

2. Lavee J, Rath S, Tran-Quang-Hoa, Ra'anani P, Ruder A, Modan $\mathrm{M}$, et al. Does complete revascularization by the conventional method truly provide the best possible results? Analysis of results and comparison with revascularization of infarct-prone segments (systematic segmental myocardial revascularization): the Sheba study. J Thorac Cardiovasc Surg 1986;92:279-90.

3. Jones EL, Weintraub WS. The importance of completeness of revascularization during long-term follow-up after coronary artery operations. J Thorac Cardiovasc Surg 1996;112:227-37.

4. Lawrie GM, Morris GC Jr, Silvers A, Wagner WF, Baron AE, Beltangady SS, et al. The influence of residual disease after coronary bypass on the 5-year survival rate of 1274 men with coronary artery disease. Circulation 1982;66:17-23.

5. Zhao XQ, Brown BG, Stewart DK, Hillger LA, Barnhart HX, Kosinski AS, et al. Effectiveness of revascularization in the Emory Angioplasty versus Surgery Trial: a randomized comparison of coronary angioplasty with bypass surgery. Circulation 1996;93:1954-62.

6. O'Keefe JH Jr, Allan JJ, McCallister BD, McConahay DR, Vacek $\mathrm{JL}$, Piehler JM, et al. Angioplasty versus bypass surgery for multivessel coronary artery disease with left ventricular ejection fraction $\leq 40 \%$. Am J Cardiol 1993;71:897-901.

7. Cosgrove DM, Loop FD, Lytle BW, Gill CC, Golding LA, Gibson C, et al. Determinants of 10-year survival after primary myocardial revascularization. Ann Surg 1985;202:480-90.

8. Boylan MJ, Lytle BW, Loop FD, Taylor PC, Borsh JA, Goormastic $\mathrm{M}$, et al. Surgical treatment of isolated left anterior descending coronary stenosis. J Thorac Cardiovasc Surg 1994;107:657-62.

9. Kaplan EL, Meier P. Nonparametric estimation from incomplete observations. J Am Stat Assoc 1958;53:457-81.

10. Blackstone EH, Naftel DC, Turner ME Jr. The decomposition of time-varying hazard into phases, each incorporating a separate stream of concomitant information. J Am Stat Assoc 1986;81:615-24. 
11. Baskerville JC, Toogood JH. Guided regression modeling for prediction and exploration of structure with many explanatory variables. Technometrics 1982;24:9-17.

12. Kirklin JW, Barratt-Boyes BG. Surgical concepts, research methods, and data analysis and use. In: Kirklin JW, Barratt-Boyes BG, editors. Cardiac surgery. New York: John Wiley; 1986. p. 177-204.

13. Ferrazzi P, McGiffin DC, Kirklin JW, Blackstone EH, Bourge RC. Have the results of mitral valve replacement improved? J Thorac Cardiovasc Surg 1986;92:186-97.

14. Loop FD. Internal-thoracic-artery grafts—biologically better coronary arteries. N Engl J Med 1996;334:263-5.

15. Lytle BW, Loop FD, Cosgrove DM, Ratliff NB, Easley K, Taylor PC. Long-term (5 to 12 years) serial studies of internal mammary artery and saphenous vein coronary bypass grafts. J Thorac Cardiovasc Surg 1985;89:248-58.

16. Zeff RH, Kongtahworn C, Iannone LA, Gordon DF, Brown TM, Phillips SJ, et al. Internal mammary artery versus saphenous vein graft to the left anterior descending coronary artery: prospective randomized study with 10-year follow-up. Ann Thorac Surg 1988;45:533-6.

17. Cameron AA, Green GE, Brogno DA, Thornton J. Internal thoracic artery grafts: 20-year clinical follow-up. J Am Coll Cardiol 1995;25:188-92.

18. Cameron A, Davis KB, Green G, Schaff HV. Coronary bypass surgery with internal-thoracic-artery grafts-effects on survival over a 15-year period. N Engl J Med 1996;334:216-9.

19. Morris RJ, Strong MD, Grunewald KE, Kuretu ML, Samuels LE,
Kresh JY, et al. Internal thoracic artery for coronary artery grafting in octogenarians. Ann Thorac Surg 1996;62:16-22.

20. Bergelson BA, Tommaso CL. Left main coronary artery disease: assessment, diagnosis, and therapy. Am Heart J 1995;129:350-9.

21. Isner JM, Kishel J, Kent KM, Ronan JA Jr, Ross AM, Roberts WC. Accuracy of angiographic determination of left main coronary arterial narrowing. Circulation 1981;63:1056-64.

22. Hermiller JB, Buller CE, Tenaglia AN, Kisslo KB, Phillips HR, Bashore TM, et al. Unrecognized left main coronary artery disease in patients undergoing interventional procedures. Am J Cardiol 1993;71:173-6.

23. Sergeant $P$, Blackstone E, Meyns B. Is return of angina after coronary artery bypass grafting immutable, can it be delayed, and is it important? J Thorac Cardiovasc Surg 1998;116:440-53.

24. Vandormael MG, Chaitman BR, Ischinger T, Aker UT, Harper M, Hernandez J, et al. Immediate and short-term benefit of multilesion coronary angioplasty: influence of degree of revascularization. J Am Coll Cardiol 1985;6:983-91.

25. Reeder GS, Holmes DR Jr, Detre K, Costigan T, Kelsey SF. Degree of revascularization in patients with multivessel coronary disease: a report from the National Heart, Lung and Blood Institute Percutaneous Transluminal Coronary Angioplasty Registry. Circulation 1988;77:638-44.

26. Faxon DP, Ghalilli K, Jacobs AK, Ruocco NA, Christellis EM, Kellett MA Jr, et al. The degree of revascularization and outcome after multivessel coronary angioplasty. Am Heart J 1992;123:854-9.

Appendix Table I. Potential risk factors examined in multivariable analysis

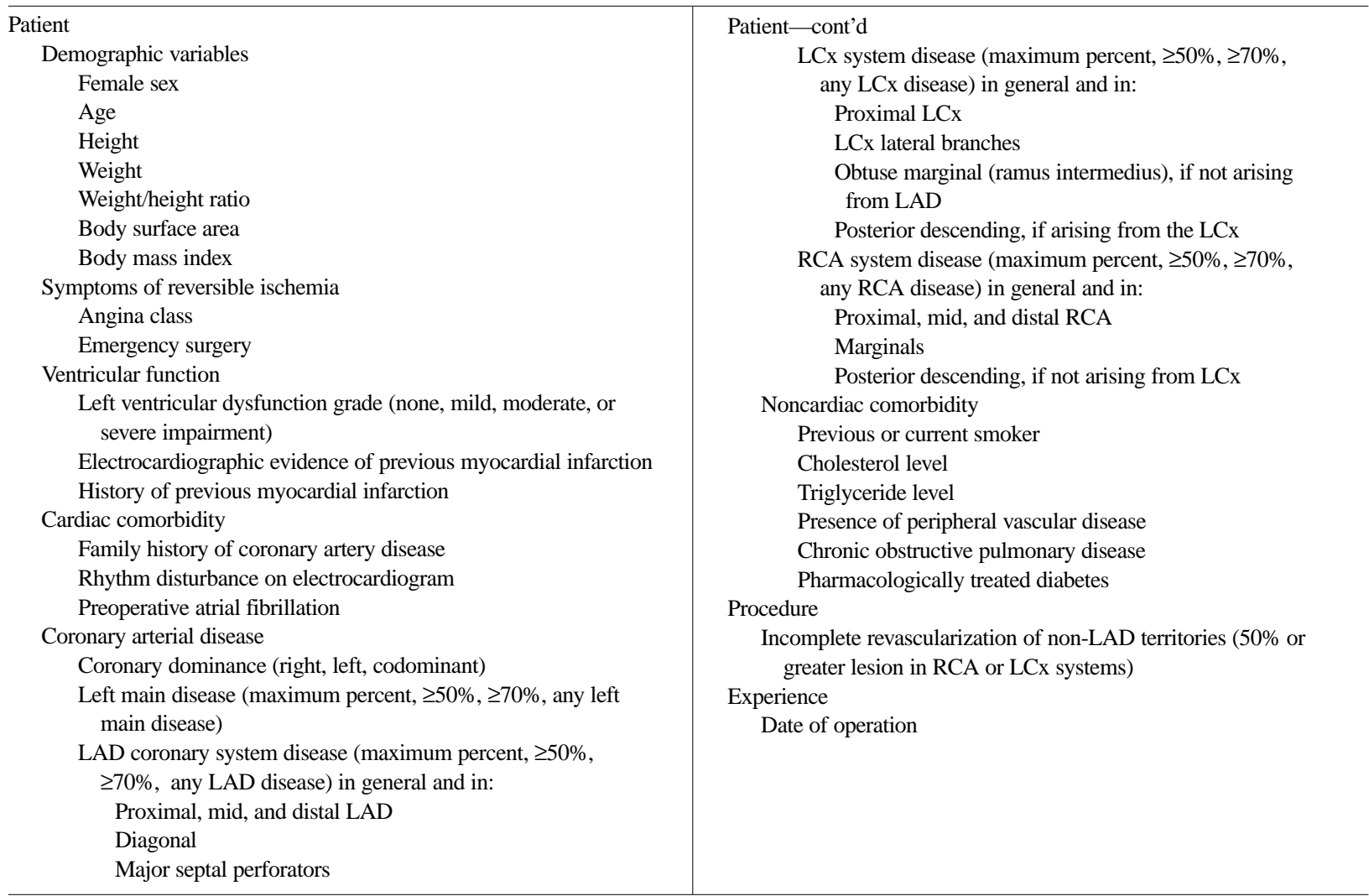




\section{Discussion}

Dr Antonio Maria Calafiore (Cheiti, Italy). This paper underlines some important points in the strategy of myocardial revascularization. First, the presence of a severe lesion of $70 \%$ or greater in the LCx territory is a crucial factor for the survival of patients. This aspect emphasizes the necessity to graft, when possible, this territory with a second thoracic artery. Strangely, the same factor was not predictive of late intervention.

Second, this same pattern is shown by any proximal lesion of the RCA of $70 \%$ or greater: negative influence on survival and no influence on late reintervention rate. However, any RCA lesion in the mid or distal portion, of any degree, had a significant impact on the reintervention rate.

Third, any residual lesion of less than $70 \%$ on the $\mathrm{LCx}$ or RCA territories did not affect survival. These conclusions allow us to draw some considerations.

The concept of complete revascularization has to be revisited in favor of the concept of adequate revascularization. This means that myocardial revascularization has to be guided by the demonstration of ischemia in the target territory when the lesion is not critical. The necessity to graft lesions if less than $70 \%$ becomes, after this presentation, less evident.

I have a comment and a few questions for Dr Scott. You demonstrated that the late negative impact of an ungrafted lesion of $70 \%$ or greater in the LCx territory or in the proximal RCA is so important that any such lesion is to be grafted during the first operation. I do not think that there is a surgeon in this room who can deny this evident truth. The purpose of minimally invasive coronary surgery is to do the same operation in a different way, not to question whether a severe nonLAD lesion has to be grafted or not.

Furthermore, the natural history of a single-vessel nonLAD disease is favorable. Since medical treatment in the United States had some practical limitation compared with Europe in the past, such as lack of availability of calcium channel blockers, and the modern interventional treatment is relatively recent, do you not think that today the data you showed are, in some way, too old?

Finally, I noticed that, for practical reasons, only $13 \%$ of the angiograms were reviewed. Eighteen percent of them showed some mistake, and often a lesion was downgraded to less than $50 \%$. No angiogram with non-LAD coronary arteries normal or with a lesion lower than $50 \%$ was examined. Do you not think that the possibility of mistake, $18 \%$, is too high and that all the angiograms need to be carefully checked before giving definite results?

Dr Scott. Thank you, Dr Calafiore, for your remarks. We would certainly agree that most surgeons in this country attempt to bypass coronary arteries with greater than $70 \%$ stenoses.

The late postoperative management of patients undergoing coronary bypass surgery has improved over time. Today more patients are treated with platelet inhibitors, and the current availability of multiple medications for altering the patient's lipid profiles is likely to improve long-term outcomes. We believe these factors are important and can diminish the progression of disease. However, incomplete revascularization is still incomplete revascularization. The main lesson of this study is that over a long period of follow-up the status of the LCX and RCA systems can influence the survival despite effective revascularization of the LAD. The LAD is not the only vessel that influences long-term survival.

In regard to your question about the angiographic accuracy of the information that we presented, we do know that the review of angiograms by multiple readers does show variability, especially in the case of left main disease. Intravascular ultrasound studies of left main disease have shown us that angiographic studies are not perfectly accurate. However, the message of this paper is not going to be changed by some variability in reading angiograms. The important message here is that as surgery evolves and as new techniques and combinations of techniques become possible, we must always remember that optimal complete revascularization is important in achieving long-term survival.

\section{Targeted}

The Journal of Thoracic and Cardiovascular Surgery gives you two tables of contents.

The condensed table of contents tells you at a glance what topics and authors are presented each month. The expanded table of contents gives you a brief abstract of each article. You select only those articles of most interest to you for further reading. 